\title{
WHAT IS LOVE? DISCOURSE ABOUT EMOTIONS IN SOCIAL SCIENCES
}

\author{
SIMONE BELLI, ROM HARRÉ, LUPICINIO ÍÑIGUEZ
}

\begin{abstract}
The study of emotions has been one of the most important areas of research in the Social Sciences. Social Psychology has also contributed to the development of this area. In this article we analyse the contribution of social Psychology to the study of emotion, understood as a social construct, and its strong relationship with language. Specifically, we open a discussion on the basis of the general characteristics of the Social Psychology of emotions and the contributions from different disciplines in this area of research, to give meaning to the relationship they have with the language of emotions. In this regard, we have reviewed basic references for the study of the construction of an emotion, and thematically classified them into three broad categories: 1) Contributions from different backgrounds and perspectives; 2) Construction and de-construction studies of emotion, and 3) Postconstructionist studies of emotion. In the first category, we consider the main contributions from the Social Sciences, which can be summarized in two areas: philosophical-construction of an emotion; mainstream-psychology of emotion. In the second category we have began with the relationship between emotion and language and the social construction of emotion, i.e., its discursive status. We end with postconstructionist theories, i.e., Butler's concept of performance and technoscience. To give more meaning to this line of research, the use of a concrete example of emotion seemed appropriate. Thus, we chose "love".
\end{abstract}

Keywords: social construction of emotion; language; performance; technoscience; love.

"The cry that we each utter in the first moment of our personal history as we are propelled from the womb into the world is an emotional signal. So emotion is the first language of us all.”

(Oatley 2007, 116)

What is sadness? What is anger? What is fear? Are they just words or is there something more? In principle, sadness, anger, and fear are emotions, and so is love. In general, it is usually considered that emotions are natural body-experiences that are then expressed through language and that language, in turn, is often described as irrational and subjective. That is, what we first feel in our bodies, later comes out of our mouths in the form of a discourse which is, in some way, opposed to reason. Emotions are also said to be gestated in the unconscious and not in the will. Thus, they are more spontaneous than artificial. They are more "sincere" than "thinking". Sometimes they are mixed with rational behaviors, whose 
existential status belongs to the order of the non-emotional. Recently, emotions have been considered not as the exclusive preservation of the individual's interiority, but as discursive social constructions. Indeed, the social Psychology of emotions has shown that the processes, causes, and consequences of emotions depend on language use. Thus, we will deal with the close relationship between emotions and language. Especially, we will deal with an emotion that has been, in the history of mankind in the Western culture, really important (Oatley 2004). We refer to "love", understood in the broadest sense. Love has helped to define the essence of human beings. "There are some who never would have loved if they never had heard it spoken of", said La Rochefoucauld. Without a history of love and lovers, we would know nothing on how to cope with such a fundamental emotion as well as on why this particular emotion has been investigated in its various aspects and the strength of the interest when it comes to the relationship between emotions and language.

For over one hundred years, emotions have been studied in several disciplines in the Humanities and Social Sciences. The topic of emotions has been studied in all branches of Social Sciences, thus there exists a large number of different theoretical approaches. For this reason, in the first part of this chapter we will address the most important contributions in three disciplines-Philosophy, Psychology, and Sociology—on the topic of emotions and its relationship with language.

In Psychology, for instance, Mayor (1988) argues that there is no commonly accepted definition of emotion, and that the history of emotions must be seen in the context of changes in Psychology as a discipline. In fact, one could say that what has most influenced the study of emotions has been the continuous change experienced by Psychology throughout its development as a discipline. And these will also influence the other two areas of study, Philosophy and Sociology. A review of emotions that does not take account of these disciplines, will give just a superficial view.

Subsequently, the language-emotion tandem has been the focus. Efforts have been made to develop arguments that serve to differentiate the relationship between these two terms; i.e., whether emotions can be "located" in language or accessed through language (Harré, Finlay-Jones, 1986; Bax 1986; Good, M., Good, B., Fischer 1988). Once we defined such a relationship, we have dealt in depth with the study of the social construction of emotions, as a natural evolution of the aforementioned binomial. The idea was to distinguish both historical and anthropological questions on how emotions are constructed (Harré 1984; Stearns and Stearns, 1985; Ibáñez 1994; Harré, Stearns 1995). Besides, our approach focuses on Discursive Psychology as proposed by Derek Edwards (1997, 2000; Edwards, Potter 1992). It must be said that Edwards is clearly influenced by the discursive approach developed by Harré (1984), Wooffitt (1992), Billig (1987), Heritage (1984), Potter and Wetherell (1987).

In recent years, research on emotions has been influenced by postconstructionist studies (Íñiguez 2005), particularly by those using performativity as a pivot concept. According to Judith Butler (1993), the construction of emotions is open to constant change and redefinition (Butler 1997; Braidotti 2000; Spivak 1990). The ultimate effect of the evolving movement of emotion and language is the notion of technoscience. Due to the use of new technologies of communication, new emotions, or different ways to draw on emotions, have emerged. The confluence of the common interests of philosophers, psychologists, and epistemologists is guided by the affective machine (Rose 1983; Brown 2005; Brown, Stenner 2001; Michael 
2000, 2006), and by notions such as cyborg, techno-disembodiment (Haraway 1989, 1995; James, Carkeek 1997; Gibbs 2006; Hollinger 2000; Ramos 2005), and "disclosure", i.e., a diffuse phenomenon referring to the meaning of expressing emotions through a screen.

Given the multiplicity of perspectives, and the open and plural theoretical and methodological controversies, as already mentioned, we will offer an overview of the scientific study of emotions as a continuous line of different Social Sciences contributions. We consider interesting to draw the line of continuity of this area of knowledge, using an example whose explanatory strength and whose impact on several researches have made us understand the importance of the relationship between emotion and language. Expressing love, i.e., being in love, has been through the history of literature a sort of statement, which has developed a whole series of myths and experiences over the centuries. For this reason, we will explore the aforementioned areas of knowledge regarding the different expressions of "love".

\section{Background}

\section{The Philosophical Character}

William Lyons (1985) provides a good starting point to introduce the topic of the Philosophy of emotion, specifically that of love. Using "love" as an example, we can connect Philosophy to Psychology, and at the same time emotion to language, which is the central theme of this chapter.

The point of looking closely at ordinary usage, if one is a psychologist, is that it often provides a clue to distinctions which it is theoretically important to take account of. We know so much about human beings, and our knowledge is incorporated implicitly in our language. Making it explicit could be a more fruitful preliminary to developing a theory than gaping at rats or grey geese (Peters 1958).

Based on this quote from Peters, Lyons $(1985,4)$ defines emotion as a functional model expressed in words. Thus, emotions are feelings directed outward and toward whatever causes them to come out. In this case, Lyons $(1985,55)$ assumes the concept of emotions as formulated by Spinoza, who asserted that we often have false beliefs about the causes of our feelings, what lead us to hate those we should love and vice versa.

Love illustrates this quite clearly. According to Lyons $(1985,186)$, we use feelings as indicators of the presence or absence of love. We say things like "don't you love me anymore?" when the other person has not shown certain feelings in settings where he or she was expected to do so. Similarly, when someone tell us "I don't feel the same for you", we can infer that it means "I don't love you anymore". It is not easy to declare your love for someone, especially if one hopes to be taken seriously and, at the same time, one tries to keep distance from the evaluative aspects of love held by the beloved one.

The work of Ludwig Wittgenstein (1958) is right in this direction by developing the discursive burden of emotions. He argues that emotions are not purely mental experiences, but also processes of identities, which identify the individual. Wittgenstein distinguishes, as Aristotle did, between the matter and the content of emotions. He states that emotions and 
psychological reactions are not two different events, but they can be described in two ways. This inseparableness of matter and form represents what is called "organizational change", i.e., the connection between emotion and object, between emotions and psychological and behavioral changes, which is logical and necessary, since a synthesis of both yields a common definition of emotion.

According to Wittgenstein (1958), we do not know our own emotions and feelings in a natural way or by observation. We produce spontaneous linguistic articulations of our feelings and impressions of the world. We express descriptive states of our affects. Wittgenstein discovered a new species of speech acts. He asserts that phrases are made up processes, away from the consecration of words and emotions in performance. In the same vein, there are new methods of the post-empirical Psychology paradigm that has been well discussed in Harré's (1989) work.

A topic of common interest for Philosophy of language and Discursive Psychology is the important role of language in the construction of emotions. According to Foucault (1966), discourse is a junction between objects and theory, and it not only produces statements, but also the power of the object in question and the materialism as redefined to include the immateriality of the body-subject. Foucault's discourse analysis permits to extract emotions from discourse to understand how the intangible effects are taken seriously in the discourse and, at the same time, given the changing conditions of speech, the contributions of such effects. This is an immaterial change inside discourse. It is an emotional change, a dynamic perspective, a vector of disturbance, and it is not considered appropriate to maintain regulatory practices and structures which have hogged the attention in ethnographic research.

In this section, we have highlighted the importance of the role of emotions in language from a philosophical perspective. As we already said, in this chapter, Philosophy is something constructed through language, and it does not exist outside discourse.

\section{From Philosophy to Psychology}

There is a blurred line between Philosophy and Psychology, especially when it comes to frame an area of knowledge such as emotions and language. For this reason, we do not want to set as a goal a demarcation between the two disciplines. We opt for a continuous interplay between them, which allows us to see an interesting set of contributions to our review.

The topic of emotions in Psychology has been studied in all its branches. There are many theoretical approaches holding different views. Mayor (1988) argues that there is no commonly accepted definition of emotion, and, for this reason, its history in Psychology should be seen in a context of continuous changes inside the discipline itself. This clarification is necessary and essential before attempting to get into the field of the Psychology of emotions. The important thing here is to have very clear that changes in the overall context of the history of Psychology have most influenced the topic of emotions. Based on this consideration, it is possible to apply psychological theories in a more general way and to try to define the specific context of the Psychology of emotions.

Likewise, many authors working in this area prefer a mainstream approach. Some of them approach the behaviorist tradition, which focuses on interactions via observation. 
Specifically, they follow the methodological standards of quantitative and positivist approaches. These authors assert that the best way to establish causal relationships is to consider that behavior is actualised in a social context. In current research, this question is picked up by another important figure in the field of study of emotions, Keith Oatley. According to Oatley, emotion is a core competence in communication, always dependent on others' intentions and actions. But this will be further developed in later sections.

In this regard, Mayor (1988) considers that the two aspects of emotion, mind and body, may be studied in an integrated way from different perspectives. Mandler (1988) argues that Psychology of emotions should address the conditions that give rise to cognitive and physiological events. It should offer an integrative perspective of the cognitivist and behaviorist approaches as parts of one Psychology of emotions. It should gather contributions that have been studied separately.

Another major trend in research on expressions of emotion is the one limited to the linguistic realm. It was developed by Russell (2003) and Wierzbicka (2008). Margaret Wetherell (1995) is the author of an important work on discourse in romantic relationships. She analyses the discourse on love and romance, the subject of love, and how certain feelings are expressed in relationships. Jackson (1994) researches on how to construct and, above all, how to handle the romantic narrative and basic instincts. Thus, he defines sex based on emotional discourses.

The work of Robert Sternberg is unavoidable in a discussion of the Psychology of love. He carried out his first research about love in the early 1980s, focusing initially on its structure: a psychometric type of theory of love (Sternberg, Grajek 1984). The problem was that the large number of disparate emotions, thoughts, and motivations, seemed to describe elements of love without systematizing them and without suggesting why anyone would love some people but not other. For this reason, the next step of his research was to formulate a new triangular theory of love, according to which, love could be understood as comprising three components: intimacy, passion, and commitment (Sternberg 1986). But in our opinion, the most important contribution of Sternberg to the Psychology of love begins in the 1990s. He began to formulate the view of love as a story. The basic idea is that we tend to fall in love with people whose stories are complementary to ours (Sternberg 1995, 1998).

Also, the work of John Alan Lee is generally considered to be a landmark in the field, and deserves a mention for his constructed ideal types differentiating between six several conceptions of intimate adult affiliation. A new interviewing method was devised to enable individuals "in love" to reconstruct their experience in codeable form: Eros, Storge, Ludus, Manía, Pragma y Ágape (Lee 1977, 1988).

We have realized how the interest for research on emotions in Psychology has grown, and how through the years such an interest has changed trends as well as the way emotion as a process is psychologically understood. Tracing this path has proved useful for bringing the reader into a more comfortable position to understand the authors' argumentation threads. This is the importance of language in the study of emotions.

As we saw in this section, the Psychology of emotions is a discipline that has given ample space to the study of emotion in the last two centuries. It is important to understand these different perspectives in the scientific context in which they have been produced. Nevertheless, each of them has contributed to and influenced considerably the topic of 
emotion viewed as a social and discursive construction in different ways. Thanks to the aforementioned scientific field, we find more comprehensible to understand how the study of emotion has had a distinct and complementary "history" in over a hundred years. This allows us to continue our review of the literature on the construction of emotion, and to provide some common coordinates for the understanding of the following sections.

\section{Construction and Deconstruction of an Emotion}

As we saw in the first part of this chapter, emotions have a strong relationship with language (Kenny 1963; Harré 1986a, 1989; Armon-Jones 1986). This particular relationship is something that can be socially constructed (Berger and Luckman 1966; Harré 1986a). Understanding emotions as social constructions is possible only through language (Bax 1986; Besnier 1990; Chance and Fiese 1999; Danes 1994). In this second part, we will see how this is possible, and how it influences our approach to the discipline.

\section{Emotion and Language}

"Le langage est [...] peut-etre un obstacle à la solitude de l'homme" (Hagège 1986, 8).

"The language (of life, not that of mathematicians), this other living language that is art, love and friendship, they are all attempts at reunite performed by the self from his island for transcending his solitude"

(Sábato 1967, 144).

Before beginning to show what the construction of an emotion consists in, we think it is appropriate to stop and think what speaking of emotion and language means. Oatley $(2007,27)$ argues that in 500 years of history of writing, emotions have been the source of most interesting arguments. Above all, there is an emotion that is the most commonly used in these 500 years of history of writing: love. Let us think for a moment of an emotional Spanish expression: "Te quiero". This phrase is used to express love for another person, the most famous examples being those of romantic novels. In their novels, authors try to put emotions in words; some authors succeed, others do not. Nevertheless, this process might be seen inversely. Some authors attempt to construct emotions through the use of words. They treat love without emotion as if it were an individual's truth. They construct a context, and give meaning to certain words, so we can talk about love. As we shall see later, they try to construct love as an emotional performance.

The great writers are continually fighting to put this emotion into their pages the way we described above. Especially, they do their best to represent the different aspects of love. It is the great task of the writer, as Bjorn Larsson, linguist and novelist, said. It is impossible to relive a great love, neither to interpret the nonverbal signs of love. All one can say is "I love you", which is a sign of no return.

In this part, we only treat one aspect of performance. We will show more details later. We try to relive the great passion of love, but paradoxically it seems that we cannot. Nevertheless, 
the use of certain words and the construction of certain contexts, allow us to recreate this performance. We can narrate this great passion, though we cannot relive it. Although it is not possible to relive it, it is possible to reconstruct this particular mood by using words. We can construct purely emotional situations, only through the use of language, thanks to such a performance.

When it comes to this "wordy" love issue, another fascinating topic is the interpretation of the great romances, i.e., the interpretation of signs, looks, gestures, which are very tenuous in performance. But, as we saw in previous paragraphs, especially in Ekman's studies, those signs are part of the body language and express emotions. Performance also requires them. Gestures, signs, and glances are weak, as they exist at the very moment of their own expression and then they disappear. And if they attempt to repeat themselves in order to achieve the same effect they are doomed to fail. Repetition is useless. It means nothing but a repetition of the phrase "I love you", a knowing look between unknown persons. Saying "I love you" is understood as an emotional performance, even if well done, i.e., saying it while caressing the neck and the ear of the beloved one. The expression of an emotion is not just a statement, but a complete performance, according to Judith Butler (1993). "I love you" is an expression of the whole body, not just a simple sentence.

The way and form of performance, like being shy for instance, influence the actual performance itself. "I love you" said by a shy person is not the same "I love you" said by a self-confident person. The words are the same, but the two performances are really distinct from each other, since persons do not express their emotion by just uttering it, but by uttering it in a certain way (Green 1970). Words are designed to produce real emotions, which might exist in the inter-subjective space.

Also, the time of reciprocity is important, the precarious moment when an individual decides to set the magic formula: "Te quiero". Here intervenes the psycho-magical element of emotions (Taylor 1972). The psycho-magic of saying "I love you" is a performance of no return (Larsson 1997). For better or for worst, after this performance the lives of any given persons can hardly return to the state prior to the pronunciation of this "formula".

\section{Study of Social Construction of Emotion}

After having defined what we mean by emotions and language, we are now at the core of this chapter, i.e., the study of the social construction of emotion. We are particularly interested in history and discourse. We will show several examples which will help us to understand the aforementioned concept of performance.

There are several authors who research on social construction of emotion from a historical point of view. The most notable are Harré (1984), Stearns and Stearns (1985), Gergen (1990), Clark (1988), Dickinson and O'Shaughnessy (1997), Kemper (1981) and Wouters (1989). The historical approach is based on studies of the evolution of "accidie" (Wenzel 1960), for example. It focuses on how this particular feeling has changed over time. We will offer more details on this by the end of the chapter. In discussing the discursive construction of love and its historical conditioning by the discourses of romantic literature, a good deal of the territory has already been covered for Niklas Luhmann and his historical studies on the "semantics of love" (Luhmann 1998). 
The second macro-level of studies on the social construction of emotion is that of the discourse. A first approach has focused on clarifying what a metaphor of an emotion is, and how it should be taken as a discursive action (Lakoff 1980). In this vein, we find some innovative and creative works (Russell 2003; Wierzbicka 2008; Gibbs 2006; Greenwood 1992; Harré and Stearns 1995; Hollander and Gordon 2006; Kövecses and Palmer 1999). These authors start from a common point: the design of emotion as a discursive construction.

Once one sees the task of understanding human behavior as involving interpretation and empathy rather than prediction or control, the self-reports of the people one is studying become very important in any psychological research project. And these should not be taken as (falsifiable) reports of states of mind but as expressions of how things are to the subject. Thus the experiment or observation has to enter into a discourse with the being studied and try to appreciate the shape of the subject's cognitive world. But at this point it no longer makes sense to talk of observer and subjects at all. There are only coparticipants in the project of making sense of the world and our experience of it (Harré and Gillet 1994, 21).

Since emotions are socially produced, they have a close relationship with language and communication (Searle 1992, 248). It has to do with the discovery of the social character of mind, which links semantics and linguistic pragmatics to our field of action, as discursive social Psychology states (Larsson 1997, 20). The social construction of emotion allows us to speak of emotions as something that can be communicated. Searle helps us to understand this in his text "The Social Construction of Reality" (1995).

\section{Discursive Psychology of Emotion}

\section{“(...) Mettre quelque chose en commun”}

(Larsson 1997, 32)

We have shown how social constructionism helps us to understand how emotions are constructed through language. Now we will focus on the psychological aspects of such a process. As Larsson asserts, emotions put things together. Emotions allow us to put things in common. For Discursive Psychology, the role of verbal interaction is crucial (Larsson 1997, 147) in the constitution and emergence of the psychic man.

The human sciences must come to terms not only with a description of the events that affect a person but also with the interpretation of those events by that very person. This entails that, for many purposes, the investigator must enter into dialogue with the subject and, of course, that dialogue will not itself be psychologically neutral in relation to the subject's thought and action. Furthermore, they enter into dialogue as "investigator" and "subject", but this is only one of the many pairs role they, as individual people, might adopt. And the perception of other aspects of their relationship may, of course, have an influence on any behavior that occurs in an experimental situation (Harré and Gillett 1994, 135).

However, as a result of this interest in the social construction of emotions, Psychology has contributed, in recent decades, to situate emotions in a new space called "discursive psychology of emotion" (Edwards 1997, 1999). Such a space corresponds to the junction of the different lines we have distinguished above. In Discursive Psychology of emotion the 
most important issue is the use of emotions in language, specifically the actions and effects of emotional speech in relational frameworks (Buttny 1993).

Discursive Psychology of emotion is based on studies, such as Oatley and Jenkins' (1992) explanation of emotion based on cognition, Coulter's (1990) sketch of the emotional sense and disposition, and finally Garfinkel's (1984) categorization of emotions according to the criteria of rationality.

In order to understand Discursive Psychology, it is necessary to return to some authors with a social constructionist background as, for instance, the contributions of Harré (1986a). Despite their agreement, Discursive Psychology and social constructionism have some differences. While Discursive Psychology has focused on the role of discourse, social constructionism has put its emphasis on social relations and their context (Cortina 2004). Lakoff (1980) and Wierzbicka (2008) have made significant contributions to Discursive Psychology. They proposed a cognitive-semantic model. Gergen (1994) finds a significant relationship between these two major perspectives, and proposes the cognitive-semantic and social constructionist model.

The main topics discussed in Discursive Psychology of emotion are perceptions, feelings, and emotions (Edwards 1997; Íñiguez 2003; Edwards and Potter 1992; Edwards 2000, 2001). Edwards (2001) gives some background for the Discursive Psychology of emotion: Pollner's (1987) disconnection from reality, Wieder's (1974) studies on the rules of drug dealers, Atkinson and Heritage's (1984) research on the exclamation "Oh!" when receiving new information, Lynch and Bogen's (1996) studies on memory and forgetfulness, and Buttny's (1993) studies on social responsibility in communication.

According to Edwards $(2001,145)$ "the Psychology of emotions is the study of how they are used and are important in emotional terms everyday speech." This definition is widely argued (Edwards 1997, 2000) and shared (Harré 1999). Edwards (2000, 2001) explores the emotional discursive investment in an extreme form, and considers that reactions are constructed as emotional reactions. The emotional reactions issue is discussed in more detail by Bamberg (2005). On Edwards' works it is important to highlight the importance of script formulations. The use of discourse analysis, specially its 10 points (Edwards and Potter 1992), is the main feature of Discursive Psychology of emotion.

For an essential bibliography on Discursive Psychology of emotion, we can highlight the following authors: Edwards (1997), Potter (2003), Billig (2001), Coulter (1990), Lynch and Bogen (1996), and Wieder (1974). What has been seen here is a representative sample of authors and their most important works inside Discursive Psychology of emotion. The next section introduces the post-constructionist approach to the study of emotion.

\section{Post-constructionism of Emotion}

After defining emotion, language, and how social constructionism and Discursive Psychology deal with them, we will focus now on post-constructionist studies, which have been quite successful in Social Sciences recently.

Post-constructionist theorists reject the constructionist explanation of the underlying structures of social phenomena. They are defined primarily following Derrida's deconstruction of the sign. 
One aspect that we found very innovative in this area is the issue of performance. It helps us to understand emotion as a changing process, which is never repeated, as love itself in romances or in real life.

\title{
Performance and Emotion
}

\begin{abstract}
"Al que toca o recita le resulta indispensable la presencia de otros: la lábil performance existe sólo si es vista o escuchada, por lo tanto, sólo en presencia de un «público»"

(Virno 2004, 42).
\end{abstract}

When it comes to the issue of performance in post-constructionist studies, the name of Judith Butler is certainly the most important. Butler (1993, 1997) deals with emotions as a constant evolution in discourse. She looks at emotions in a completely new perspective through the concept of performance. Although in her text the term "emotion" is not explicit, it arises spontaneously in all of her discourses and positions.

Using the concept of performance, Butler (1993) explores how discourse creates a need for particular emotions: "Such acts, gestures, enactments, generally constructed, are performative in the sense that the essence or identity that are intended to express manufacturing constituted and sustained through corporeal signs and other discursive means" (Butler 1993, 136). In this way, emotion is a performance produced by these fabrications, which are internally discontinuous acts. That is to say, emotions do not exist prior to their performance, and success of the copy, or "repetition" of an emotion previously performed, can never be invoked to faithfully reproduce that event, i.e., a new emotion.

These events or "fabrications" are seen as natural by repeating over time a set of multiple everyday life interactions. These performative acts are open to constant change and redefinitions. Acts or "fabrications" (Butler 1993) eventually become standards that can be seen as natural.

The notion of performance in Butler's work is indebted to John Austin (1955). When she mentions the concept of performativity in language, certainly we must mention John Austin's work, especially one of his most famous works "How to do things with words" (1955), which by the way is relevant to our research. Austin distinguished three types of acts that can be done with words, called locutionary, illocutionary, and perlocutionary. Saying something is a locutionary act, but at the same time it is an illocutionary act and sometimes a perlocutionary one. Butler is interested in perlocutionary acts that establish that saying is doing. Saying something generates effects and consequences on feelings, on thoughts and actions, on self and on others. Austin referred to feelings and emotions contained in conventional performative acts, and illocutionary aspects produced in a performative way. The notion of performance used by Judith Butler, continues to be a locutionary act. The implicit point in Austin's work is that performance depends on "happy" utterances, i.e., when its structure is part of its circumstances. Butler takes this notion and widens it, giving it the strength and power that these actions have on the speaker and on others and, above all, their capacity to produce intended changes and transformations. 
Butler is interested in perlocutionary acts, i.e., when saying something produces effects and consequences on feelings, thoughts or actions of self and others.

Another important concept for Butler (1993) is iteration. She uses Derrida's theory of iteration because of how it deepens the understanding of performance: "Performativity cannot be understood outside of an iterative process, a regulated and limited repetition of norms. (...) This means that the iterative performance is not an act or event, singular, but a ritualized production (...)" (Butler 1993, 95). In short, it is "a stylized repetition of acts" (Butler 1993, 140).

The concept of performativity in Butler is therefore an attempt to find a way to rethink the relationship between social structures and individual agencies. In Butler's interpretation, performativity is understood as that which promotes and supports the implementation process through an iterative repetition subject to certain rules. Such standards should be understood, as argued earlier, in the design of joint Wittgensteinian spontaneous linguistic sensations. Equally, we should understand that utterances are purely spontaneous processes (Wittgenstein 1958). Since rules are valid only in some context, and for some people only, they cannot be duplicated for different situations. The politics of performativity requires the iterative power of discourse to produce the phenomenon of emotion, since emotion does not exist before one says something, i.e., before producing a speech act.

In our research we explored how these "fabrications" "do" emotions. Thus, emotions are designed as socially constructed phenomena. They are socially constructed identities that indicate how the audience must behave (Butler 1993). As explained above, these emotions do not pre-exist to their performance, and cannot be reused and categorized and quoted in the future (Gregson and Rose 2000, 438).

Butler argues that gender is created through performance and suggests that gender is not a fixed identity or a given series of different acts. Rather it is an identity constructed through time and space through an iteration of stylized acts (Butler 1993).

Performative acts are constructed by iteration, by persistence and stability and by the possibility of rupture, of change, of deconstruction too. However, performance is not just an actuation, a staging. According to Butler, iteration introduces at once the temporality of a subject. It is not a singular act or event, but a ritualized production, an iteration of a ban under certain conditions, a taboo. The subject is never completely determined (Femenía 2003). Right there, as Femenía (2003) asserts, the political capacity anchors itself and processes of statements can reinstate new meanings. Strictly speaking, the strength of the drift of its performance breaks with the past contexts and the ability to take new ones is unlimited.

Indeed, getting distance from Austin and Derrida, Butler argues that what constitutes the real strength of performance is not consistent with the formulation of any of them. However, both views, taken together, led to the proposal of a theory of social iterative speech acts. Speech is not like writing, says Butler, because the body is present in speech in a different way than in writing, but also because the relationship between body and speech, though oblique, actualizes in the same expression. Although writing and speaking are both acts of the body, the mark of the body that reads a text not always makes clear who owns the body. The speech act actualizes in the body. The simultaneity of the production and externalization of expression not only report what is said but shows the body as the instrument for rhetoric 
expression. According to Felman, who Butler quotes, the excess of discourse should be read with and against the prepositional content of what is said. Then, the relation between speech act and body act puts into its rightful place the body, its gestures, its aesthetic, and its unconscious knowledge as the site of the reconstruction of practical sense, without which social reality cannot be constituted as such. Finally, in order to externalize an emotion a sentence is not enough. According to Judith Butler, a complete performance is needed. "I love you" is an expression of the body as a totality, not just a simple phrase.

The concept of performance, for example, applied in the stories of schizophrenic patients (Leudar 2007), allows us to understand the iteration. Leudar analyses the "voices" schizophrenic patients hear, and how changes in the stories, continually appearing, disappearing and changing shape and intensity, are never the same. These "voices" can be understood as emotions that are never at the same level of violence and presence for patients with schizophrenia. Also, they are useful to understand the process of iteration that constitutes the performance.

It is important to understand that "performativity is not a single act, but a repetition and a ritual which achieves its effects through its naturalization in the context of the body" (Butler 1993, 15). The body is not a "fact" (Butler 1993), but a variable boundary, politically regulated. It is a significant practice. This allows us to speak of emotions in technoscience, in terms of techno-disembodiment and machine, which has much to do with "corporality", as discussed below.

Moreover, Butler proposes a crucial distinction between expression and performance. Acts, in their various ways, produced or presented by the body, are performative, have their cultural significance, and do not have a pre-existing identity that can be measured. Acts cannot be true or false, real or apparent.

So acts, gestures, and codes in general are performative in the sense that the essences and identities expressed are fabrications manufactured and sustained through corporeal signs and other discursive means (Butler 1993, 136). It does not mean that for Butler the body is reducible to language but that language emerges from the body (Butler 2004, 198). Thus, we can say that the concept of performativity is not prepared "only for acts of discourse, but also for physical acts" (Butler 2003, 198). The relationship between the two is quite complicated. In order to tackle such a difficulty Butler introduces the term "chiasmus" (Butler 1993). It states that "there is always a physical dimension of life that cannot be fully represented" (Butler 2003, 199).

Butler adds that speech is inseparable from the body due to the illocutionary force underlying each issue. Speech is made of bodily acts. If any speech act is performed, it communicates not only a literary message but a bodily one, since the body is a privileged rhetorical instrument of expression. An act is a performative and discursive practice, in the sense that it is a linguistic act constantly subject to interpretation. The performative act must be performed as a play, presented to an audience and interpreted in accordance with predetermined rules. In turn, the performative act produces an effect, i.e., constructs reality as a result of the performed act (Butler 1997a).

Performance has not only been used for studies of gender. There is a vast narrative on the concept of performance in Social Sciences. Thus, in recent years some geographers have used performance to explain, for example, the social construction of identity in human 
geographic areas (Gregson and Rose 2000, 434). In the construction of identity, performance plays a central role. It is made of looks, personalities, and emotions, and it is manipulated by identities. "Kind" or "friendly" are concepts that have been modified and handled by different people (Guyatt 2005). Victoria Guyatt (2005) proposed a gender study on workers at a pub in New Zealand, and distinguished among their emotions. Girls were moving in a completely positive emotional context, were categorized as funny, pretty, and extroverted. On the other hand, boys had to appear as "violent, aggressive, strong, and kicking ass." These two different constructions of gender identity have to be seen as a steady and progressive performance of workers at a pub. These fabrications are what Butler (1993) calls an emotional gender identity. These acts are simply a natural iteration of a performance over time. They are, in many ways, the interactions of everyday life (Butler 1993). Performance is regulated, but it is unstable, and it is altered by subjective views that may be adopted throughout the performance itself.

Averill (1982) asserts that emotions are social roles. He emphasizes the performative role of emotions and takes into account the emotional discourse implying emotions in themselves. For example, one can consider love as an emotion, a subsequent performance. "Falling in love" is nothing but a fabrication of the world like any other. James Averill (1982) suggests that emotions are improvised. They are based on the individual's interpretation of the situation. These improvisations and interpretations occur in social contexts in everyday experiences.

\section{The Performance of Emotions Over Time}

In this last part of the chapter, and after having defined the various steps for understanding how emotions have a strong relationship with language, especially following the concept of performance, we will now focus on the meaning of all this, and what are the "effects" in everyday discourse. As we saw earlier, in social constructionism there are two perspectives, the historical and the discursive. In the historical, emotions change over time, and such a change is due to discourse. Both views have are part of a discipline called Discursive Psychology. This change, this evolution, of emotions (including their disappearance) can be understood only through post-constructionist studies. Performance helps us to understand why some emotions appear and others disappear in ordinary language. Since emotions are narratives, they are action stories (Oatley and Jenkins 1992, 75).

Emotions are a bodily experience that cannot be separated from the socio-cultural contexts in which we find ourselves. This is why we consider important to see how emotions change over the years. It is a way to understand emotions in a historical-discursive framework, and to see the changes into time. This vision can also be understood as a performance in everyday discourse. There are emotional terms which our generation no longer uses, but other terms are used which have replaced earlier ones in the discursive arena. Thus, emotions become obsolete, outdated, completely "out". Emotions evolve or disappear over time, and always led by the concept of performance in our daily stories. Each language offers us examples of emotions that have disappeared, that are not in our discourse anymore. For example, the term "accidie" is extinct in the discursive arena.

In use from the thirteenth century until the sixteenth century, today the term accidie is synonym of laziness, disinterest, but is not equivalent to any of them. Accidie refers to 
feelings associated with loss of intrinsic motivation towards our own religious duties (Robert, 2003: 245). In literature one can find the term "accidie" in "Don Quixote", by Cervantes. The term accidie has been rescued in recent years by Giorgio Agamben (1995) to describe the state that lies between mourning and melancholy: "Throughout the Middle Ages, a scourge worse than the plague that infects castles, the villas, and palaces of the city's world tilts on the houses of the spiritual life, enters the cells and in the cloisters of monasteries in the tebaidas of hermits in the rags of the prisoners. Acedia, tristitia, taedium vitae, desidia are the names that the Fathers of the Church gives to induce death in the soul." Accidie also belongs to the seven deadly sins, and it was often related to God (Edwards 1997). But in our days it is completely missing as an emotion, and it is very difficult to find it in everyday discourse. Now there are other synonyms like laziness, but it is not the same. Thus, the term "accidie" disappeared in contemporary usage.

Another example is the term "melancholy". Our ancestors made frequent use of this word many times to express a certain emotion, but our generations do not (Robert 2003, 160). It is very easy to remember our grandparents pronouncing this term in their stories, but we no longer use it. It seems that melancholy has gone out of fashion. It does not appear in our everyday discourse. Neither does it appear in songs even though in a not too distant past a frequent use of this term was made. Melancholy is now replaced in everyday language with words such as sadness, depression, and loneliness.

These two examples were used to support the theory that emotions have to be interpreted in the social context in which they occur. Thus, it is no wonder that emotions come and go in the discursive arena. It is a steady performance that makes new feelings appear in the discursive arena.

Robert $(2003,160)$ argues that emotions create actions, especially those concerning the words that generate them. In this sense, emotions, or words referring to emotions, are not the same in a classroom at the University of Chicago or in a monastery in the medieval Spain (ibid., 183). They change over time and space, i.e., they change depending on the context in which they are generated.

Emotions change in natural and spontaneous language of everyday life. New words enter the discursive arena, thanks to a performance that has never been tried before, and then new areas are produced. For instance, emotions begin to enter the technological language as another performance in everyday discourse. Love stories in front of a flat screen are typical of everyday life.

The concept of performance related to ICT represents a new narrative in Social Sciences, coining concepts like techno-disembodiment and affective machine. Only in recent years have emotions and new technologies been understood to have a very close relationship, especially on the subject of intimacy. This is evident from the interviews with users of cyber-cafes made by the GESCIT project — an immigrant mother, who cries while speaking on the phone with her children and family at home; a young immigrant who "parties" with some friends from his motherland through the Internet; or two young lovers, separated by a thousand miles, who have a chat conversation.

Since emotions are bodily experiences that cannot be separated from the socio-cultural contexts in which we find ourselves, we consider important to emphasize that emotions have changed over the years. Emotions have to be understood in a historical perspective in order 
to see their changes in time. This vision can also be understood as a performance in daily discourse. There are emotional terms our generation no longer uses, but we use other terms that have replaced earlier ones in the discursive arena. Why do emotions become obsolete, outdated, completely out? Emotions evolve or disappear over time, and so does performance in our daily stories. Each language offers us examples of emotions that have disappeared, that no longer exist in our discourse.

\section{The Last Emotional Frontier: Techno-science}

We understand emotions in this chapter as a textual practice, as a semantic evolution. Thus, some of the aims of a researcher in this field would be to find in emotional discourse forms of contemporary life. He or she can take a historical perspective showing how the discourse of emotions is related to a socio-linguistic field. We understand that performance is subject to the power of the discourse of emotions. Emotional discourse contains new concepts and metaphors to articulate and understand emotions in the lexicon. Concepts such as techno-disembodiment or human-affective machine are parts of the techno-scientific side of emotions, and are examples of a new performance, new emotions that appear in the discursive arena.

The examples we have shown in the preceding paragraph are used to support the theory that emotions have to be interpreted in the social context in which they occur, so there is no wonder if emotions come and go in discursive arena. Mike Michael (1996, 2000, 2004, 2006), with a clear semiotic method, recognizes emotions as affective matter.

Techno-science is also related to the semantic concept of embodiment, but it considers its cognitive treatment, and emphasizes the communicative and linguistic turn. The main authors working in this direction are Haworth (1990), Niedenthal, Barsalou, Ric, and KrauthGruber (2005), Prinz (2005), Lyon (1999), Katz (1996), Harré in his text "The Necessity of Personhood as Embodied Being" (1995), Malin and Peterson (2001) and Haworth (1990).

The embodiment concept also has a more extreme sense, the case of technodisembodiment., a concept studied by James and Carkeek (1997a, 1997b).

These different discourses on affections and emotions in technoscience can be seen in the context offered by Nicholas Rose (1983) who introduces the concept of emotional material and the figure of the machine that constructs the individual, i.e., the affective machine. This vision is also embodied by the figure of Haraway's (1990, 1995) cyborg and Hollinger (2000). Also Gergen (1990) gives a reinterpretation of emotional material in the postmodern society.

Steve Brown and Paul Stenner (2001; Brown 2005) speak of collective emotions in technoscience and of consumer society, by using the writings of Spinoza as well as those of more recent authors like Schaub (1933), and specifically the notion of affective material becoming a human-machine.

When you deal with emotions and language in technoscience, especially if you focus on love, there is a very important aspect, disclosure (Aviram, Amichai-Hamburger 2005; Qian, Scott 2007), which is one of the key issues we have found throughout our analysis and in our research group. Disclosure refers to what fascinates us when talking to a stranger or to someone we already know, when we are facing a computer screen. Such a fascination allows 
us to say things we would never say in person, especially if we talk in terms of affectivity. This is why using these technologies in different aspects of life is so successful. Phenomena such as Facebook, ensures contact with someone who one already knows, but going into a more intimate mode in which we can express our hidden emotions. And this is achieved through the language, through the performance, which allows us to rethink relationships, and intimate with new technologies. Now we are aware of emotions when we are in front of a flat screen. Disclosure is the main emotion that technology causes us. If we think about these emotional-affective processes, we understand the fundamental importance of these aspects in relationships.

Technology measures, quantifies, and identifies emotional states and the communication of these emotions between people and consequently between machines in real time. The concept of techno-disembodiment as defined by Paul James and Freya Carkeek is "an increasing abstraction of the way we live our bodies and widespread technological mediation of social relations" (Carkeek and James 1997, 107). Carkeek and James argue that the strength of this concept is related to an emotional charge attached to the residual erotic-romantic, such as techno-sexuality. Sex without the presence of another person or the representation of a technological sexual organ, the wide range of telephone-sex practices and sex chat-up, as well as cosmetic surgery, are examples that illustrate an emerging development and widespread feature of postmodern times. These practices are part of the broader phenomenon of techno-disembodiment.

According to Healey and Gould (2001) the affective machine constructs technological systems that can interact with humans and transmit bio-psychological changes, for instance, using shoes, bracelets, t-shirts, etc. These objects receive and transmit changes to the individual, specifically emotional states attached to social contexts. These gadgets are only a phase in man-machine interaction, i.e., the affective human-machine (Healey and Gould 2001).

Consumption of technologies may be taken as a possible emotion. The simple term "iPod" expresses an emotion in our daily stories. Emotions regarded as consumer products are one aspect that has been successfully developed in research during the last decade (Belli, Íñiguez 2008). As mentioned above, emotions not only become obsolete, but new formulations occur within the discursive arena.

\section{Discussion}

As we already said (Belli, Íñiguez 2008), emotions have a strong relationship with language. We can express emotions through language. Thus, we believe it is essential to show how different disciplines have made important contributions to this theory, especially in Philosophy, Psychology, Sociology, and Linguistics.

All these fields have looked at the social construction of emotions. It is important to understand that it is impossible to speak of the social construction of emotions without taking into account this background and these contributions.

As we have said throughout this chapter, expressing emotions means putting something in common with others. We have also seen how an emotional performance, such as love, changes through historical discourse. Regarding performance, love always depends on 
the non-verbal gestures, and how the other responds. Something in these gestures, in its performance, does not get repeated in the same way. Such gestures cannot pass the word. Everything becomes real in the intersubjective emotional space. Thanks to the concept of performance, developed by Judith Butler, emotions are not something fixed, defined, and static. They are constantly evolving, continuously complying with an iteration process, and they do it through language, natural and subjective. This constant iteration makes emotions appear and disappear from the discursive arena, leaving some forgotten (accidie) and discovering new others (technoscience). We consider emotions as a constant evolution in daily discourse. This evolution has its highest expression in technoscience. In fact, the term emotion can be associated with very specific areas in technoscience, and thus emotional expressions come into play in the discursive arena. The emergence of concepts such as techno-disembodiment, or the emotional connection between individuals and new technologies, i.e., the concept of machine-affective of Nikolas Rose, are just some examples of what we introduce in the current scope of technoscience. Finally, the concept of disclosure is useful to help us think about love in the age of technoscience.

We can conclude by saying that we have outlined in this bibliographic review, the possibility of a contingent relationship between emotions and language, and considered it as a break or a continuation from social constructionism to post-constructionism, in which we find the concept of performance of Judith Butler, and the relationship between emotion, language, and their variations. The last aspect of performance is its approach to technoscience. We find impossible to speak of technoscience and performance without considering the whole process. For this reason, we wanted to make this journey, to reach these conclusions, as we will move forward with our future research on the topic of emotion and language in new technologies.

Bauman (2006) argues that emotions are variable and slippery. They lose momentum very quickly. They tend to be diverted from the original purpose to the slightest distraction. Love is like thirst, it always ends being quenched. Emotions are fickle and change completely. The crowds formed to lynch someone, sometimes may feel moved by a merciful feeling. There are many emotions and they speak with different, and often discordant, voices. This is why Max Weber in his most famous work The Protestant Ethic and the Spirit of Capitalism (1903) mentioned them as a key reason for the good survival of society, because reason, unlike emotions, is one and has a unique voice. Since emotions are a continuous performance, every attempt to repeat them is doomed to fail. As we know, love is variable and changes continuously. It is never the same. We cannot find a single definition of love shared by everyone. Performance is continuous and constant. Each individual has a version of love, which changes continuously over time as well as the person who is in love changes too.

\section{References}

Agamben, G. Homo sacer: Il potere sovrano e la nuda vita. Bologna: Einaudi, 1995.

Armon-Jones, C. The Thesis of Constructionism. In R. Harré (Ed.). The Social Construction of Emotion. Oxford, UK: Basil Blackwell, 32-56, 1986.

Atkinson, J. M., Heritage, J. Structures of Social Action: Studies in Conversation Analysis. Cambridge: Cambridge University Press, 1984. 
Austin, J. How to Do Things with Words. Cambridge: Cambridge University Press, 1955/1998.

Averill, J. Disorders of Emotion. Journal of Social and Clinical Psychology 6, 247-268, 1988.

Aviram, I., Amichai-Hamburger, Y. Online Infidelity: Aspects of Dyadic Satisfaction, Selfdisclosure, and Narcissism. Journal of Computer-Mediated Communication 10, 45-69, 2005.

Bamberg, M. Narrative Discourse and Identities. Narratology Beyond Literary Criticism: Mediality, Disciplinarity. Cambridge: Cambridge University Press, 2005.

Bauman, Z. Liquid Fear. Cambridge: Polity Press, 2006.

Bax, M. M. H. Discourse Analysis and Discourse Training: The Complementary Relationship between Language Use Theory and Language Proficiency Training. Spektator 16, 350-368, 1986.

Belli, S., Íñiguez-Rueda, L. El estudio psicosocial de las emociones: Una revisión y discusión de la investigación actual. PSICO 39, 139-151, 2008.

Berger, P., Luckmann, T. La construcción social de la realidad. Buenos Aires: Amorrortu editores, 2003/1966.

Besnier, N. Language and Affect. Annual Review of Anthropology 19, 419-451, 1990.

Billig, M. Arguing and Thinking: A Rhetorical Approach to Social Psychology. Cambridge: Cambridge University Press, 1987.

Bourdieu, P. Outline of a Theory of Practice. Cambridge: Cambridge University Press, 1977.

Braidotti, R. The Way We Were: Some Post-structuralist Memoirs. Women's Studies International Forum 23, 715-728, 2000.

Brown, S.D. Collective Emotions: Artaud's Nerves. Culture and Organization 11, 235-247, 2005.

Brown, S. D., Stenner, P. Being Affected: Spinoza and the Psychology of Emotion. International Journal of Group Tensions 30, 81-105, 2001.

Butler, J. Bodies that Matter: On the Discursive Limits of Sex. London: Routledge, 1993.

Butler, J. Excitable Speech: A Politics of the Performative. London: Routledge, 1997.

Butler, J. Gender Trouble. Continental Feminism Reader. London: Routledge, 2003.

Buttny, R. Social Accountability in Communication. London: Sage Publications, 1993.

Chance, C., Fiese, B. Gender-stereotyped Lessons about Emotion in Family Narratives. Narrative Inquiry 9, 243-255, 1999.

Clark, C. The Social Construction of Emotions. American Journal of Sociology 94(2; 2), 415-417, 1988.

Cortina, A. The Jealousy Passion: A Semiotic Discourse Analysis. Alfa: Revista de Linguistica 48, 7994, 2004.

Coulter, J. Mind in Action. Oxford: Oxford Press, 1990.

Danes, F. Involvement with Language and in Language. Journal of Pragmatics 22, 251-264, 1994.

Dickinson, R., O'Shaughnessy, J. Reviews and Communication. Journal of Macromarketing 17, 116, 1997.

Edwards, D. Discourse and Cognition. London: Sage Publications, 1997.

Edwards, D. Extreme Case Formulations: Softeners, Investment, and Doing Nonliteral. Research on Language \& Social Interaction 33, 347-373, 2000.

Edwards, D. Emotion Discourse. Culture \& Psychology 5, 271-291, 2001.

Edwards, D. D., Potter, J. Discursive Psychology. London: Sage, 1992.

Ekman, P. Emotion in the Human Face. New York: Cambridge University Press, 1982.

Femenías, M. L. Judith Butler: Introducción a su lectura. Barcelona: Catálogos, 2003.

Foucault, M. Las palabras y las cosas. México: Siglo XXI, 1966.

Foucault, M. L'uso dei piaceri. storia della sessualitá 2. Milano: Feltrinelli, 1984.

Garfinkel, H. Studies in Ethnomethodology. Cambridge: Polity, 1984. 
Gergen, K. Affect and Organization in Postmodern Society. In S. Srivastva, D. L. Cooperrider (Eds.). Appreciative Management and Leadership: The Power of Positive Thought and Action in Organizations. Washington: Jossey-Bass, 153-174, 1990.

Gergen, K. Realities and Relationship. Cambridge: Harvard University Press, 1994.

Gibbs, R. W. J. Embodiment and Cognitive Science. Cambridge: Cambridge University Press, 2006.

Good, M. D., Good, B. J., Fischer, M. M. J. Introduction: Discourse and the Study of Emotion, Illness and Healing. Culture, Medicine and Psychiatry 12, 1-7, 1988.

Green, O. The Expression of Emotion. Mind 5, 551-568, 1970.

Greenwood, J. D. The Social Constitution of Emotion. New Ideas in Psychology 10, 1-18, 1992.

Gregson, N., Rose, G. Taking Butler elsewhere: Performativities, Spatialities and Subjectivities. Environment and Planning D, 18(4), 433-452, 2000.

Guyatt, V. Research Article Gender Performances in a Service Orientated Workplace in Aotearoa/New Zealand. New Zealand Geographer 61, 203-254, 2005.

Hagège, C. La structure des langues. Paris: Presses universitaires de France, 1986.

Haraway, D. Primate Visions: Gender, Race, and Nature in the World of Modern Science. New York: Routledge, 1989.

Haraway, D. Ciencia, cyborgs y mujeres: La reinvención de la naturaleza. Valencia: Publ. Universitat de Valencia, 1995.

Harré, R. Social Elements as Mind. British Journal of Medical Psychology 57, 127-135, 1984.

Harré, R. Varieties of Realism: A Rationale for the Natural Sciences. London: Blackwell, 1986.

Harré, R. Language and the Science of Psychology. Journal of Social Behavior \& Personality 4, 165188, 1989.

Harré, R., Finlay-Jones, R. Emotion Talk across Times. In R. Harré (Ed.). The Social Construction of Emotions. London: Sage, 220-223, 1986.

Harré, R., Stearns, P. N. Discursive Psychology in Practice. London: Sage, 1995.

Haworth, J. T. The Embodyment Theory of Pre-Reflexive Thought and Creativity. In K. J. Gilhooly, M. T. G. Keane, R. H. Logie \& G. Erdos (Eds.). Lines of Thinking: Reflections on the Psychology of Thought, Vol. 2: Skills, Emotion, Creative Processes, Individual Differences and Teaching Thinking. London: John Wiley \& Sons, 203-215, 1990.

Hollander, J. A., Gordon, H. R. The Processes of Social Construction in Talk. Symbolic Interaction 29, 92-120, 2006.

Hollinger, V. Cyborgs and Citadels/Between Monsters, Goddess, and Cyborgs. Signs: Journal of Women in Culture \& Society 25, 577-601, 2000.

Ibañez, T. Constructing a Representation or Representing a Construction. Theory and Psychology 4, 363-382, 1994.

Íñiguez, L. Análisis del discurso. Barcelona: UOC, 2003.

Íniguez, L. Nuevos debates, nuevas ideas y nuevas prácticas en la Psicología social de la era 'postconstruccionista'. Athenea Digital 8, 24-60, 2005.

Izard, C. E. The Psychology of Emotions. London: Springer, 1991.

Jackson, J. Chronic Pain and the Tension between the Body as Subject and Object. In T. J. Csordas (Ed.). Embodiment and Experience: The Existential Ground of Culture and Self. Cambridge: Cambridge University Press, 201-228, 1994.

James, P., Carkeek, F. Techno-disembodiment. Virtual Politics: Identity and Community in Cyberspace. London: Springer, 1997.

Katz, J. Families and Funny Mirrors: A Study of the Social Construction and Personal Embodiment of Humor. American Journal of Sociology 101, 11-94, 1996.

Kemper, T. D. Social Constructionist and Positivist Approaches to the Sociology of Emotions. American Journal of Sociology 87, 336-362, 1981. 
Kenny, A. Action, Emotion, and Will. London: Routledge, 1963.

Kövecses, Z., Palmer, G. B. Language and Emotion Concepts: What Experientialists and Social Constructionists Have in Common. In G. B. Palmer, D. J. Occhi (Eds.). Languages of Sentiment: Cultural Constructions of Emotional Substrates. London: John Benjamins Publishing Company, 237-262, 1999.

La Rochefoucauld, F. Máximas: reflexiones o sentencias y máximas morales. Barcelona: Planeta, 1665/ 1984.

Lakoff, G. Metaphors We Live By. Chicago: University of Chicago Press, 1980.

Larsson, B. Le bon sens commun. Lund: Lund Univ. Pr., 1997.

Lee, J. A Topology of Styles of Loving. Personality and Social Psychology Bulletin 3, 173-182, 1977.

Lee, J. Love Styles. In R. J. Sternberg, M. L. Barnes (Eds.). The Psychology of Love. Yale: Yale University Press, 1988.

Luhmann N. Love as Passion: the Codification of Intimacy. Stanford: Stanford University Press, Trans. by J. Gaines, D.L. Jones, 1998.

Lynch, M., Bogen, D. The Spectacle of History. Speech, Text and Memory at the Iran Contra Hearings. Durham NC: Duke University Press, 1996.

Lyon, M. L. Emotion and Embodiment: The Respiratory Mediation of Somatic and Social Processes. In A. L. Hinton (Ed.). Biocultural Approaches to the Emotions. Cambridge: Cambridge University Press, 182-212, 1999.

Lyons, W. Emotion. Cambridge: Cambridge University Press, 1985.

Mandler, G. Historia y desarrollo de la Psicología de la emoción. In L.Mayor (Ed.), Psicología de la emoción.(Teoría básica e investigaciones). València: Promolibro, 1988.

Mayor, L. Psicología de la emoción. Teoría básica e investigaciones. Valencia: Promolibro, 1988.

Michael, M. Constructing Identities: The Social, the Nonhuman and Change. London: Sage, 1996.

Michael, M. (Ed.). Reconnecting Culture, Technology and Nature: From Society to Heterogeneity. London: Routledge, 2000.

Michael, M. Reconnecting Culture, Technology, and Nature: From Society to Heterogeneity. London: Ebrary, 2004.

Michael, M. Technoscience and Everyday Life: The Complex Simplicities of the Mundane. New York: Open University Press, 2006.

Niedenthal, P., Winkielman, P. (Eds.). Emotion and Consciousness. New York: Guilford Press, 2005.

Oatley, K. Breve storia delle emozioni. Bologna: Il Mulino, 2007.

Oatley, K., Jenkins, J. M. Human Emotions: Function and Dysfunction. Annual Review of Psychology 43, 55-85, 1992.

Peters, R. S. The Concept of Motivation. London: Routledge \& Kegan Paul, 1958.

Pollner, M. Mundane Reason: Reality in Everyday and Sociological Discourse. Cambridge: Cambridge University Press, 1987.

Potter, J., Wetherell, M. Discourse and Social Psychology: Beyond Attitudes and Behaviour. London: Sage, 1987.

Prinz, J. J. Emotions, Ebodiment, and Awareness. In L. F. Barrett, P. M. Niedenthal, P. Winkielman (Eds.). Emotion and Consciousness. New York: Guilford Press, 363-383, 2005.

Qian, H., Scott, C. R. Anonymity and Self-disclosure on Weblogs. Journal of Computer-Mediated Communication 12, 1428-1451, 2007.

Ramos, J. O. Lengua, cultura y escritura en la sociedad virtual. Tres décadas de red-acción (19712001), Círculo de Lingüística Aplicada a la Comunicación, 8, 24-51, 2001.

Roberts, R. C. Emotions: An Essay in Aid of Moral Psychology. Cambridge: Cambridge University Press, 2003. 
Rose, N. Effects o Rational Emotive Education and Rational Emotive Education Plus Rational Emotive Imagery on the Adjustment of Disturbed and Normal Elementary School Children. Ann Arbor, MI: ProQuest Information \& Learning, 1983.

Russell, J. A. Core Affect and the Psychological Construction of Emotion. Psychological Review 110, 145-172, 2003.

Sàbato, E. El escritor y sus fantasmas. Madrid: Aguilar, 1967.

Sartre, J. P. Bosquejo de una teoría de las emociones. Madrid: Alianza, 1971.

Schaub, E. L. Spinoza: His Personality and his Doctrine of Perfection. Monist 43, 1-22, 1933.

Searle, J. R. The Rediscovery of the Mind. Cambridge: MIT Press, 1992.

Soyland, A. Psychology as Metaphor. London: Sage, 1994.

Spivak, G. C. The Post-colonial Critic. New York: Routledge, 1990.

Stearns, P. N., Stearns, C. Z. Emotionology: Clarifying the History of Emotions and Emotional Standards. The American Historical Review 90, 813-836, 1985.

Sternberg, R., Grajek, S. The Nature of Love. Journal of Personality and Social Psychology 47, 312329, 1984.

Sternberg, R. A Triangular Theory of Love. Psychological Review 93, 119-135, 1986.

Sternberg, J. Love Stories. Personal Relationships 3, 59-80, 1995.

Sternberg, R. Love is a Story: A New Theory of Personal Relationships. Oxford: Open University Press, 1998.

Virno, P. Cuando el verbo se hace carne. Madrid: Traficantes de sueños, 2004.

Watts, S., Stenner, P. The Subjective Experience of Partnership Love: A Q Methodological Study. British Journal of Social Psychology 44, 85-107, 2005.

Weber, M. La Ética protestante y el espíritu del capitalismo. Buenos Aires: Fondo de Cultura Economica, 1903/2003.

Wetherell, M. Romantic Discourse and Feminist Analysis: Interrogating Investment, Power and Desire. In S. Wilkinson, C. Kitzinger (Eds.). Feminism and Discourse: Psychological Perspectives. London: Sage, 1995.

Wierzbicke, A. A Conceptual Basis for Research into Emotions and Bilingualism. Bilingualism: Language and Cognition 11, 193-195, 2008.

Wooffitt, R. Telling Tales of the Unexpected: The Organization of Factual Discourse. London: Harvester/Wheatheaf, 1992.

Wouters, C. The Social Construction of Emotions. Theory, Culture \& Society 6, 704-707, 1989.

Despacho 311 mód. IV bis,

Departamento de Lingüística General,

Lenguas Modernas, Lógica y Filosofía de la Ciencia,

Teoría de la Literatura y Literatura Comparada

Universidad Autónoma de Madrid

Ciudad Universitaria de Cantoblanco

28049 Madrid

Tel.: +34 914976823

E-mail: simone.belli@uab.es

and

Psychology Dept, Georgetown University,

Washington, DC 20057

USA

E-mail: harre@georgetown.edu 
and

B5-034 Dept. de Psicologia Social

Universitat Autonoma de Barcelona

08192 Bellaterra (Cerdanyola)

Spain

E-mail: lupicinio.iniguez@uab.cat 